\section{Método proyectual tradicional y su aplicabilidad en el contexto de ambientes virtuales de aprendizaje}

\author{
María Dolores Cevallos Sánchez ${ }^{(1)}$
}

Resumen: Es posible aplicar el método proyectual tradicional en los ambientes virtuales de aprendizaje. Es una interrogante repetida desde el momento coyuntural de cambio que se está viviendo. Más allá de si es o no aplicable, la respuesta es que necesariamente se tiene que adaptar y evolucionar, en concordancia.

Desde un enfoque de materias proyectivas, dentro del campo del Diseño Gráfico, donde se deben desarrollar propuestas tangibles desde una base conceptual, es inevitable trabajar con el método proyectual, en una modalidad de taller que requiere una constante retroalimentación de los avances del proyecto. Esto tiene sentido en tanto y cuanto se pueden dilucidar progresos y correcciones sobre la propuesta planteada por el estudiante. Al estar mediados por una tecnología que salva la distancia, los problemas existen, sobre todo al no estar "ahí" ambas partes, docente y alumno para discutir. Todo se hace en una pantalla. No se boceta ni esquematiza tangible ni directamente, esto se agrava si la clase no se da en sincronicidad.

Se propone que la adaptación de la TIC que media el proceso dependa también de la adaptación del método del docente. Haciendo énfasis en el nuevo protagonismo del profesor cuya identidad es hoy por hoy, una pantalla omnipresente en todos los ambientes del estudiante. La idea es encontrar los puntos medulares de una resignificación del docente como una nueva imagen apoyada en un lenguaje audiovisual en donde la modificación tanto del modelo pedagógico como actitudinal en los encuentros sincrónicos y asincrónicos puedan ser provechosos dentro del perfeccionamiento curricular.

Palabras clave: Tecnología - Ubicua - Omnipresencialidad - Aula invertida.

[Resúmenes en inglés y portugués en las páginas 69-70]

(1) María Dolores Cevallos Sánchez. Adscrita a la Pontificia Universidad Católica del Ecuador, en la Carrera de Diseño Gráfico de la Facultad de Arquitectura, Diseño y Artes. Diseñadora por la Pontificia Universidad Católica del Ecuador (PUCE), Máster en Dirección de Comunicación Corporativa (DirCom) por la Universidad de las Américas (UDLA). Docente a tiempo parcial de la Carrera de Diseño de la PUCE. Código ORCID: 0000-0002-9545-9257 


\section{Introducción}

La premisa, el modelo tradicional de la didáctica en Diseño Gráfico promueve un diálogo permanente entre el docente y el estudiante, una constante retroalimentación que propone los cambios, replanteos y directrices que va tomando el proyecto en su desenvolvimiento. Dentro del contexto actual, coyuntural, el punto sobre el cual el presente trabajo se centra es en dilucidar las diferentes estrategias que atañen al nuevo elemento mediador que no existía en el aula tradicional, la pantalla. Toda actividad de retroalimentación se da en un tiempo y espacio mediado por un artefacto, ya no son los actores en sí mismos, es ahora, el medio por el que se miran, dialogan y discuten, una imagen y sonido. Esto conlleva que la manera de relacionarse sea concebida desde otros ángulos de acción, que va a estar encerrada en el plano de las TICs. Todo lo expuesto anteriormente radica dentro de lo que se denomina tecnología ubicua. Citando a García (2015).

La tecnología ubicua potencializa el aprendizaje en todo lugar y en cualquier momento -'any time, any were' - a partir de la informática cercana a la persona, de ahí la expresión. La característica principal de esta tecnología es la integración del aprendizaje y la tecnología. En la tecnología ubicua está determinada por la integración de la informática en el entorno de la persona, de forma que los ordenadores de las computadoras, además de no percibirse, son utilizados a favor de: aprendizaje silencioso, trabajo colaborativo, intercreatividad, intercambio creativos digitales, inteligencia colectiva, inteligencias emergentes, sabiduría de las multitudes, etc. (p. 70).

La manera en que se puede entender a este nuevo lenguaje mediado por la tecnología, es justamente desde el aprovechamiento de este espacio, diferente, sí, pero que permite comunicarse en imágenes a quien está del otro lado, tanto ideas, contenidos y retroalimentaciones propias de la clase. El éxito de este modelo radica en que los contenidos sean de tanto interés y fuerza que lo que media, la pantalla, no se sienta ni se perciba, por lo tanto no sea un limitante, es que el principio pedagógico mismo que caracteriza a las tecnologías ubicuas es el dejar de poner atención al aparato para centrarse en asimilar los contenidos. Este es un esquema de interacciones controlado cuyo propósito en el proceso enseñanza aprendizaje radica en lo que García (2015) denomina: "Las dimensiones de la puerta de entrada de las TIC". Estas dimensiones dentro de las cuales se pueden y se deben gestionar los nuevos espacios de aprendizaje virtuales mediados la TICs son los siguientes:

a. Gestión y planificación. Cómo organizar el desarrollo curricular relacionando tanto el soporte digital que media el proceso como la forma final que se visualizará. Los argumentos que soportan este principio de planificación son el uso inteligente de espacios virtuales, sustentado en el sistema computacional.

b. Desarrollo profesional de los docentes. La capacitación hacia los docentes sobre el manejo de las plataformas que le dan sentido al modelo ubicuo son esenciales para establecer 
las relaciones entre contenidos curriculares y soporte virtual.

c. Cultura digital en la institución escolar. El desarrollo de un entendimiento digital depende también del desarrollo en recursos e infraestructura de las TICs por parte de la institución, tanto en capacitaciones como se menciona líneas arriba como en actualizaciones de las plataformas. (p.71)

El docente y la institución que lo enmarca, hoy más que nunca deben ser conscientes de que cada imagen que construyen con información, tiene una función especial, no solo de comunicar, sino de captar, mantener la atención y diálogo durante un periodo específico de tiempo. Para el presente análisis se pretende establecer nuevos caminos y conceptos relacionados a la una nueva unidad de comunicación ubicua, la pantalla, que hoy por hoy media todo el sistema educativo e inevitablemente obliga a modificar el discurso, que clásicamente se sostenía cara a cara, en el aula. Eso es lo que se puede entender como una nueva cultura en el aula virtual, un nuevo reconocimiento del manejo de recursos digitales tanto del docente como de la institución y cómo estos se proyectan hacia la comunidad del alumnado, sea que requieran esfuerzos adicionales y coyunturales de actualización o no.

\section{Del aula a la pantalla y la nueva omnipresencia del docente}

El medio audiovisual que "intermedia" entre docente y estudiante es una herramienta compleja, compuesta por varias dimensiones. Es un ambiente virtual, definido en un soporte físico, la pantalla, que proporciona información desde una planificación de la clase, siguiendo un orden cronológico de los contenidos curriculares y un soporte digital, un software, un programa por medio del cual se maneja y esquematizan los dichos contenidos. Esto desemboca en un ambiente construido, pensado para que la actividad estudiante profesor se de sincrónica y asincrónicamente, sabiendo que la participación de cada actor, es un complejo de interacciones que se dan con encuentros y desencuentros, ya que el carácter sincronicidad no siempre significa un encuentro real, si el profesor mantiene una estaticidad en la pantalla y los alumnos no hablan, no necesariamente es un encuentro. No siempre se ven, no siempre se atienden, no siempre dialogan mutuamente, pero lo que sí visualizan siempre, es el medio, el monitor y el programa que le da forma. Entonces si el medio físico es una pantalla, y lo que permite el funcionamiento de este medio es la plataforma, el correcto desempeño del proceso de aprendizaje depende tanto del óptimo uso de la herramienta, el software, como también del modo en que se va creando estas “imágenes" en los que se comunica cada actor con el otro. Todo este entender del modelo pedagógico virtual actual en una dimensión física y virtual, se corrobora en lo manifestado por García (2015).

Entre los dispositivos móviles utilizados con frecuencia que posibilitan el aprendizaje ubicuo están, por un lado los cursos desarrollados en línea $-e$ learning-, los cursos desarrollados a través de electrónicos móviles -m-lear- 
ning-, los cursos en línea semipresencial -b-learning- y los cursos de aprendizaje ubicuo - $u$-learning-. Por otro, los recursos existentes y elaborados con fines pedagógicos, entre ellos se encuentran: los softwares -libres y privados-, la enciclomedia, las redes inalámbricas, las computadoras de bolsillo, los smarthphones, los teléfonos inteligentes y las tablets. (p.71)

Como se menciona anteriormente el componente físico de los modelos de aprendizaje en línea como el móvil, y el software que viene a ser lo intangible, son partes esenciales de los nuevos procesos de educación y su evolución y adaptaciones al sistema de la virtualidad responden al diestro manejo de las herramientas tanto del docente como del estudiante. Pero esto no lo es todo, manejar tanto el componente físico como el virtual no garantiza los encuentros de aprendizaje. Si bien esta unidad de lenguaje, la imagen, es producto de la mediación de la TIC, y la traducción tradicional del docente frente a ella es esta. Ver Figura 1. La interrogante es: cómo extrapolar esta imagen convencional a una imagen dinámica que converia en diálogos. intercambios v memorias constructivas bara los estudiantes.
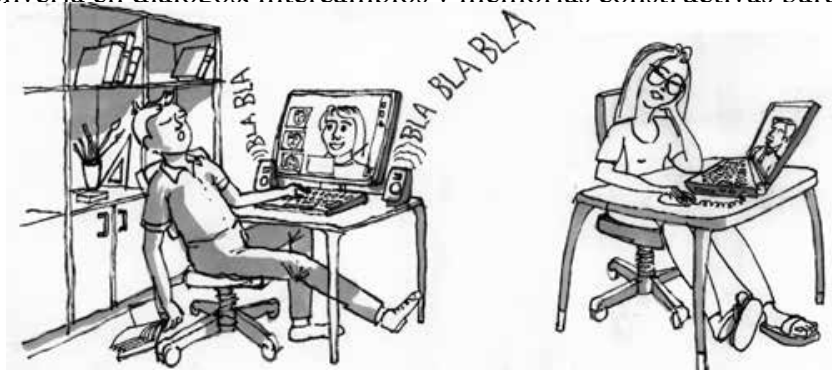

Figura 1. Docente en pantalla. Nota: Elaborado por M. Dolores Cevallos.

La presencialidad del docente se resumió, a un cuadro con su imagen, en un plano que propiamente en el lenguaje cinematográfico es denominado plano medio corto, mostrando desde su cabeza hasta un poco más debajo de los hombros, cuya característica es quedar parcialmente inmóvil varias horas, con un sonido como de radio un poco mal sintonizado dependiendo de la calidad de internet que cada actor posea. Ni en la telenovela menos recursiva visualmente el plano del protagonista es tan inmóvil, en la entrevista televisada más estática existen movimientos de cámara aunque sea para saludar o dar un anuncio (De Santiago, 2017, p.17). Es que si se va a repensar en la nueva manera de presencialidad de las clases, pues hay que pensar necesariamente en la forma de la imágenes que uno como docente proyecta, en la forma de las unidades visuales que se pretende comunicar. Esta es la presencialidad actual del docente, casi omnipresente en los espacios del alumno. Las pantallas están activas en todos los entornos, en el dormitorio, el comedor hasta en 
las oficinas de los padres del mismo, como se cita arriba a García 'any time, any were'. Paradójicamente a esta omnipresencialidad existe otro factor que hace que este rasgo que juega a favor pueda estancarlo. Es la posible estaticidad de la imagen. Como se explicó líneas arriba la visualización del profesor en una forma estática y continua tendrá un efecto monótono, que el lenguaje audiovisual lleva modificando desde los inicios mismos de la creación de la imagen en movimiento, el cine. Son casos como uno de los primeros cortos de los hermanos Lumiere, La llegada del tren, donde en un poco más de un minuto se muestra el aparecimiento en perspectiva de un tren, primero como un punto para luego volverse una imagen ampliada que impresionó a más de uno pensando que este saldría de la pantalla. Ese ojo táctico de la construcción de la imagen en movimiento fue lo que históricamente hizo la diferencia (Narváez Torregrosa, 2004, p.33). No se busca en este estudio el proponer un dominio de tomas y escenas por parte del profesor, pero si el dilucidar varios puntos en los que el docente diseñador, pueda hacer uso de sus propios recursos y construir esta nueva presencialidad más allá del plano de su propia persona hablando un par de horas. Es una omnipresencialidad que nunca en la historia se había tenido, la pantalla llegó a la casa de los estudiantes y con todo el lenguaje que esta implica.
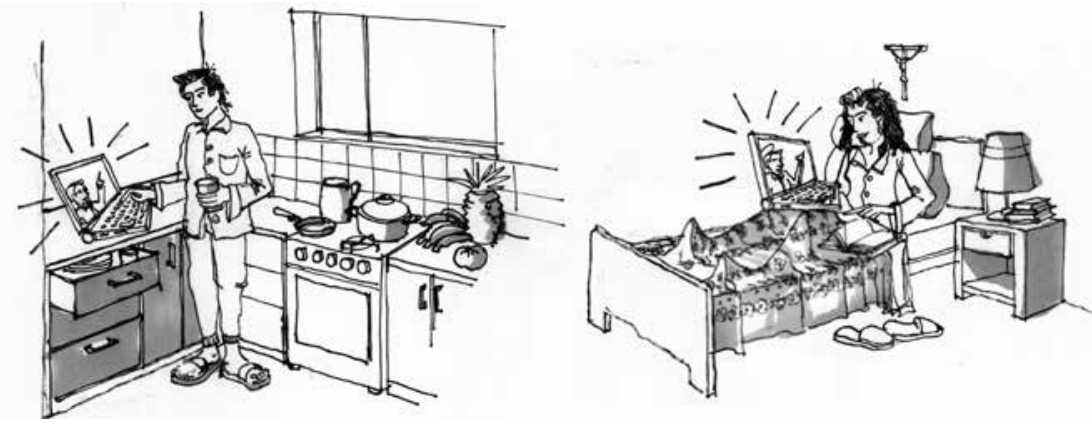

Figura 2. Nuevo profesor omnipresente. Nota: Elaborado por M. Dolores Cevallos.

En este trabajo se presentan estas consideraciones que rompan la estaticidad para desarrollar una educación en esta era cada vez más tecnologizada, en espacios virtuales con sus propias dinámicas, en la cual se convive con nuevos actores autónomos físicos (pantallas) y virtuales programados y programables por los usuarios, con sistemas basados en la intuición, la creatividad, las sensaciones y las emociones (Rama, 20171, p.52). Retomando esta dimensión de la creatividad y las sensaciones se considera que el apoyo gráfico es fundamental, se habla sí, de proyección de elementos claves para fortalecer los contenidos de la materia. La diapositiva en sí misma es una secuencia de imágenes y contenido. Qué sucedería, si dicha secuencia se crea desde otra óptica, no desde el plano fijo sino desde la propuesta de interactividad con los estudiantes. Si bien la diapositiva muestra informa- 
ción también puede proponer participación, desde el movimiento mismo del docente y provocando ese mismo movimiento en el estudiante. Son estrategias comúnmente usadas en actividades lúdicas intermedias en extensas clases magistrales para despertar la atención y romper la monotonía, sería entonces la misma estrategia pero el desafió hoy, es pensarlo dentro de un monitor.

Dentro de la propia dinámica de la TIC que está mediando el proceso, cuál es la necesidad de que el profesor esté estático y no pueda moverse dentro del plano acercándose a lo que sería el contenido de su diapositiva. Se está proponiendo una presencialidad distinta, quizá una más activa que permita indicar otros recursos, por ejemplo, la pizarra, esquemas gráficos, mood boards, planos técnicos, que pueden y deben ser la respuesta. No es algo que no se haya hecho ya en las aulas convencionales meses atrás en la era prepandemia, más bien es recordar estas acciones y llevarlas a la pantalla, ya sea que conlleve un esfuerzo organizativo logístico o no. Queda aún mucho camino por recorrer para construir estos nuevos espacios sociovirtuales educativos que permitan integrar la educación formal, no formal e informal, sin embargo se deben dar estos primeros pasos. (Rama, 2017, p.61). Este es un primer planteamiento que, desde luego, es discutible, pero que trata de alentar la reflexión sobre un futuro anunciado y al que no se puede permanecer indiferentes.

\section{La pedagogía inversa, una ventaja para el método proyectual}

En este punto de reflexión sobre la nueva presencialidad docente, ya no solamente en el aula sino en el hogar, y en casi todo espacio donde se desarrolla el estudiante, cabe preguntarse: ¿Se puede considerar que los modelos educativos tradicionales son aplicables en el contexto de ambientes virtuales de aprendizaje?

Es una pregunta que más de un docente se ha hecho desde el momento coyuntural de cambio que se está viviendo. Más allá de responder si son o no aplicables a esta nueva presencialidad en pantalla, la respuesta es que necesariamente se han tenido que adaptar y evolucionar juntos. En esta emergencia sanitaria, la manera tradicional de llevar una clase cambió y los modelos pedagógicos se han ido adaptando. Citando a Calatrava (2019, p.1) en su artículo sobre Transformación digital en la educación y flipped classroom o aula invertida, "La modalidad de blended learning es justamente una mezcla entre las clases tradicionales y las clases virtuales, con el objetivo de ayudar a que los estudiantes alcancen mejores resultados."

Se puede entonces, decir que el modelo tradicional es aplicable y estratégico en tanto evolucione al entorno virtual, ahora, es fácil decirlo, pero cuál sería la ruta. Siguiendo las sugerencias del mismo autor sobre las dinámicas de la flipped classroom o aula invertida, los tiempos sincrónicos de clase, los tiempos de encuentro con los estudiantes son invalorables y deben usarse desde la lógica de la optimización. La presencialidad del docente está ahí en la pantalla, pero su estaticidad se debe romper y se puede transmutar con las siguientes acciones:

1. Aplicación de estrategias para aprovechar el tiempo. Esto implica que el estudiante pre- 
viamente haya revisado y estudiado los contenidos, en el caso del método proyectual en Diseño Gráfico además debe proponer avances del proyecto.

2. Centrar la atención en el estudiante y dedicar estos tiempos sincrónicos en esclarecer dudas.

3. Fomentar el debate.

4. Proponer una mayor autonomía del estudiante en su proceso de aprendizaje.

Los ambientes virtuales, necesariamente obligan al profesor a proveer este espacio con todo el material de una forma anticipada y organizada de tal forma que la navegación del estudiante es lo que prime. En este sentido es recomendable y lógicamente aplicable, que el alumno sea dueño de su tiempo y dueño de cómo y cuándo manejar su asimilación de contenidos. Citando al mismo artículo de flipped clasrroom $(2019$, p.1) "Sin embargo, flippear una clase es mucho más que la edición y distribución de un video. Se trata de un enfoque integral que combina la instrucción directa con métodos constructivistas, el incremento de compromiso e implicación de los estudiantes con el contenido del curso y mejorar su comprensión conceptual." Inevitablemente este modelo requiere del compromiso del estudiante, pero está en el docente y su proceso de construcción y comunicación del aula, el brindarle las instrucciones y el tiempo de adaptación para el uso óptimo de la misma.

Ahora siendo más conservadores y estrictos en la significación de los modelos educativos tradicionales y si estos son aplicables y estratégicos en el contexto de ambientes virtuales de aprendizaje, la respuesta sería no. Lo que eventualmente sucedió con los modelos educativos tradicionales abruptamente aplicados a la virtualidad, es que interpretaron al entorno virtual como un simple repositorio de documentos a nivel on line, y fue debido a la emergencia sanitaria que esta óptica se desarrolló porque el espacio a la reinterpretación de los modelos fue escaso (García, 2007, p.37). Pero si se quiere crear un ambiente virtual que esté realmente al servicio del aprendizaje, es la pedagogía inversa (flipped classroom en inglés) uno de los caminos. Los espacios y momentos de aprendizaje son distintos desde una óptica estrictamente virtual, como se inició manifestando, el profesor no está pero al mismo tiempo sí está por medio de la pantalla en todos los ambientes del estudiante. Este cambio presupone una oportunidad desde la pedagogía inversa, no se puede reducir al docente a un proveedor de documentos, videos y archivos en la plataforma, recordemos que ya está reducido a un "plano" estático, entonces es desde el uso de las Tics en el modelo mismo de la plataforma donde el docente debe intervenir y remodelar la interacción. La propuesta consiste en que, desde la pedagogía inversa se resignifique al modelo tradicional. Esta resignificación se caracterizará por entender 3 fundamentales momentos:

\section{Primer Momento}

En primer lugar, repensar a la "La clase frontal". El estudio individual y evaluación de lo aprendido en clase, es el modelo clásico que se vivía en las aulas en la era prepandemia, y en las actividades proyectuales tanto en la clase frontal como en asesorías, éstas, se veían 
enriquecidas por procesos de retroalimentación directos, estudiante profesor, sobre las artes, bocetos, esquemas del proyecto ya sea grupal o individualmente. En esta lógica clásica, tradicional, el estudiante antes de asistir a clase no sabía nada o sabía muy poco de los contenidos y aprendía durante el desarrollo de las mismas clases y avances del proyecto. Profundizaba sobre lo que se abordaba, a través de varias tareas desarrolladas individualmente en casa, y obviamente con sus propios avances del proyecto, ya sea en fases investigativas, fases definitorias, desarrollo de alternativas, o fases finales, acompañados de otros métodos como exposiciones, debates, evaluaciones de tribunales examinadores, etc. Si bien esto se puede ir desarrollando desde las nuevas vías, las pantallas, en la pedagogía inversa todo eso se puede revolucionar, las clases y encuentros sincrónicos se convierten en momentos en los cuales el tiempo debe ser más productivo y funcional y se centra en activar las competencias cognitivas altas (comprender, aplicar, evaluar, crear) de los estudiantes. Esto implica que el estudiante previamente venga con un estudio y comprensión desarrollados para que en cada encuentro sincrónico se puedan dilucidar puntos de avance en el conocimiento. En esta óptica, el desarrollo de los modelos proyectuales tienen una ventaja en esta evolución obligatoria en los ambientes virtuales. Tanto docentes como estudiantes de Diseño Gráfico ya están habituados en una proporción mayor o menor de acuerdo a su nivel cursante, a una dinámica de investigación y avances de desarrollo del proyecto. Este ya es un paso adelante dentro de lo llamado flipped classroom. El estudiante de Diseño no es estático, pasivo esperando recibir los conocimientos como se da en la clase tradicional, este ya tiene puntos de inicios en los establecimientos del problema de Diseño como punto de partida y de las directrices del docente depende la ruta y guía para ir avanzando en sus fases.

Eso ya sucedía en las aulas tradicionales basadas en los métodos proyectuales, entonces se está en ventaja estratégica frente a los nuevos modelos de pedagogía inversa, porque de algún modo los estudiantes ya venían y vienen con procesos de aprendizaje autónomo dentro de las fases de desarrollo de proyectos y de los cuales siempre han sido protagonistas. Se recuerda lo planteado por García (2007), el objetivo de la educación ya no está dirigido a la transmisión de conocimientos sino, a la consolidación de destrezas y competencias que aporten a cada persona los medios necesarios para acceder a la información y posteriormente transformarla en conocimiento, creación e innovación.(p.33)

Es importante aprovechar esta ventaja que se puede definir en dos momentos: el primero el de poder traducir a las aulas virtuales todas las directrices de planteamiento del proyecto para que el estudiante pueda nutrirse de esta información siendo dueño de su tiempo de aprendizaje y el segundo ya definido en progresos y avances del mismo dados en los encuentros y asesorías sincrónicas estudiante-profesor. Y como se realizaba en las aulas tradicionales de Diseño, ir estableciendo las asesorías y retroalimentaciones grupales o individuales, pero con los anticipados avances y aportes autónomos del estudiante. La palabra clave en este desarrollo y remodelación dentro del aula es el proceso autónomo del estudiante de diseño como proyectista.

Entonces dentro de las propuestas pedagógicas del flipped classroom, en donde se propone que el estudiante ya viene a clase preparado a través de las herramientas y de las estrategias tecnológicas, planificadas por el enseñante, se puede concluir que es algo que en las aulas de Diseño ya se proponía y era deber del estudiante acudir a la siguiente clase con sus propuestas claras dentro de su proceso y el docente, que es más bien un tutor, acom- 
pañaba en el espacio de la clase. Desde esta lógica el estudiante puede poner en práctica lo aprendido, a través de la solución de problemas prácticos propuestos por el docente, cuya tarea es guiar al estudiante en la elaboración activa y en el desarrollo de tareas complejas. Por esa razón el modelo inverso transfiere la clase a la casa, y más que a la casa como espacio, a la "casa" como espacio-tiempo individual del alumno. Y el papel del docente es el de tutor en un ambiente colaborativo individual y grupal. En este punto la pedagogía del proceso proyectual también pone al docente de Diseño en un momento de ventaja. En los momentos de encuentro, docente y estudiante en las aulas prepandemia, este tomaba el papel de asesor dentro del proyecto, corrigiendo, guiando en los métodos y herramientas desarrolladas por el estudiante, apoyando a su proceso individual y en la búsqueda de la solución propia de diseño. Es que es la naturaleza misma de los contenidos del proyecto de Diseño que obligan al docente siempre y en todo momento a respetar los procesos creativos y de desarrollo del estudiante y es en este desarrollo respetuoso de crecimiento donde cada docente ha podido ir dilucidando sus propias estrategias de motivación y exigencia en los grupos para que lleguen a buen puerto con el diseño. Entonces se puede hablar que desde la metodología misma proyectual se pueden empatar aristas dentro de lo propuesto en la pedagogía inversa y más que poner al docente diseñador en un momento de incertidumbre y vacilación lo pone en una posición ventajosa donde puede ir rescatando estas estrategias y remodelarlas en la nueva realidad y presencialidad, mediada por el monitor.

\section{Segundo Momento}

El segundo momento, es entender que la pedagogía inversa en el aula universitaria es dirigida a un estudiante adulto. Entonces, cabe en este punto preguntarse, ¿Por qué este modelo es recomendable para la educación superior? El principio mismo de la flipped clasroom, destaca y propone el que sea direccionada a adultos, y desde una percepción de la adultez global y completa, es decir con responsabilidad plena de sus procesos cognitivos. Es desde este enfoque de responsabilidad autónoma donde el estudiante de Diseño también juega en una posición de ventaja en el método proyectual. El desarrollo de un proyecto de Diseño Gráfico con todo lo que ello implica, desde la definición del problema de diseño, la investigación, procesos creativos, alternativas y etc., involucra un proceso autónomo y responsable que ya se viene llevando desde los niveles donde el alumno ya es dueño de sus proyectos. Es responsable y autónomo desde la concepción misma del diseño donde el proceso cognitivo no es mecánico tradicional de lectura y apropiación, sino que es de proposición, de autoría y creatividad individual, buscando su propia identidad y lenguaje gráfico.

\section{Tercer Momento}

Y el tercer momento se da dentro de los ambientes virtuales en una combinación táctica 
de tres características primordiales en el proceso cognitivo para adultos, desde la perspectiva de la pedagogía invertida: la participación, la horizontalidad y la flexibilidad.

La participación está garantizada por actividades planificadas fuera de y durante la clase, que propicien la interacción entre estudiantes con el tutor, como ya se ha anotado anteriormente, son los momentos de correcciones sobre avances en las fases proyectuales. Estos estamentos son el pan de cada día para cualquier docente en Diseño que ha propuesto el método proyectual en sus clases. Las actividades planificadas fuera de la clase son siempre los avances sobre el proyecto, son el desarrollo de las soluciones de Diseño que va creando el alumno. Y las clases directas frontales con el profesor se van dando en asesorías, tutorías de acuerdo a las propuestas del estudiante en sincronizidad en las videoconferencias. Se recalca, de acuerdo a las propuestas del estudiante ya que sin este trabajo autónomo el proyecto no avanza. Entonces, como se dice anteriormente, son las metodologías docentes que se atañen al proyecto lo que converge con los principios de la pedagogía inversa y que pone al proceso de Diseño en un posición ventajosa en este nueva reinterpretación de las clases donde se convirtió al aula en un pantalla.

Retomando a la horizontalidad, se puede decir que se da en los espacios donde el rol del docente cambia, es más un mentor o un facilitador del proceso de aprendizaje, un aliado para los estudiantes, de esa manera, el ambiente creado es de pares. Es un momento donde trabajar desde la perspectiva del docente en Diseño, es vital, totalmente medular que el profesor tome la postura de mentor, de partidario y no de inspector del proyecto. Es verdad que el proceso del estudiante puede ser incipiente dependiendo del nivel que esté cursando pero el papel del docente diseñador debe ser de constructor y no de crítico lapidario. Esto sí ha sido un aspecto en el que se debe trabajar desde los mecanismos de examinación y análisis del proyecto, desde métodos como tribunales examinadores, rúbricas controladas y asesorías de retroalimentación. La búsqueda de puntos de encuentros en los que el docente sea un aliado del proyecto son importantes.

El aspecto de la Flexibilidad es entendida en la pedagogía inversa como un eje que trasforma la clase en un momento más productivo, permite dar tiempo al tutor de seguir de manera personalizada a los estudiantes con ritmos de aprendizajes diferentes o que tienen algunas problemáticas especiales. Igualmente como en los puntos anteriores este es un momento de convergencia del docente diseñador, con este nuevo modelo. Todo docente que ha seguido el método proyectual sabe, conoce y reconoce que dentro su metodología de clase debe proponer los horarios de asesorías personalizadas y de este seguimiento individual depende los avances y culminaciones de los proyectos. Como se ha mencionado anteriormente es como el pan de cada día del docente en los procesos proyectuales y son momentos y metodologías que deben ser rescatadas. Los docentes se convierten en tutores en las aulas de e-learning y tienen que incluir las acciones siguientes, actualizar su perfil, esta acción ayuda a humanizar el contacto entre los participantes y da una sensación de estar dialogando con otras personas. Siempre, responder dudas o consultas en un tiempo controlado, planificar sesiones, establecer comunicación a través de diferentes canales: mensajería, foros. (García, 2015, p.72)

Desde estas reflexiones propuestas y tratando de traducir a puntos específicos, se puede traducir a que el aprendizaje en aulas virtuales requiere acciones de constante comunicación bidireccional, estudiante profesor y para ello se pueden seguir las siguientes reco- 
mendaciones:

1. Revisar y usar todos los Canales de Comunicación, oficiales propios del Entorno Virtual como los más coloquiales. Se debe plantear en las políticas del aula cuáles serán los canales de comunicación, horarios, y promover la revisión diaria de los mismos en los estudiantes. 2. Seguimiento Continuo de los canales de comunicación propuestos. El seguimiento continuo de los espacios de interacción en el Aula Virtual es clave. Para que no sea demandante para el docente y fuera de horarios depende de una planificación clara de la misma. 3. Definir dónde estarán ubicados en el Entorno Virtual de Aprendizaje: tiempos de entregas, herramientas, tareas, dudas.

4. Motivación al Alumno. Se propone plantear Actividades de análisis, síntesis, participación colaborativa, lúdicas con el fin de que participen activamente en la construcción del aprendizaje. Este tipo de motivaciones si bien deben ser adaptadas y resignificadas al método proyectual propio del Diseño Gráfico, se deben hacer, se deben buscar los espacios para articularlas. Desde la pedagogía inversa se proponen actividades cómo: mapas mentales, nube de palabras, mapas conceptuales, grupos participativos.

5. Retroalimentación Oportuna. Es vital la retroalimentación constante en base a sus avances del proyecto, aprendizaje, dudas, clases sincrónicas y asincrónicas. Como se ha señalado anteriormente estos si son rasgos del método proyectual en una modalidad de taller, por lo tanto deben mantenerse y afianzarse. Es importante la utilización de medios cómo: mail institucionales, mensajes en EVA, whatsapps dentro de políticas de uso del aula virtual.

6. Tutorías Académicas fuera de horario si se considera necesario. Dentro de las planificación curricular de las clases se contempla espacios para asesorías o tutorías particulares ya sean grupales o individuales fuera del horario de clase y que se dan en el tiempo y espacio de mutuo acuerdo docente, estudiante. Estos momentos se deben aprovechar como uno más de comunicación bidireccional que aporte tanto al desarrollo autónomo de los estudiantes en asimilar los contenidos ya que serán espacios de refuerzo de conocimientos como también de dudas o recuperaciones. Se debe recordar que al depender de las plataformas y del medio audiovisual, la pantalla, se está propenso a fallas técnicas fuera del control del estudiante, y el prever espacios de encuentro donde se solventen estos desencuentros es parte de la planificación curricular.

\section{Características del tutor omnipresente}

Otro apartado dentro de esta nueva concepción del docente ya no como un actor, frente a frente y cara a cara al estudiante sino como una nueva identidad en una pantalla, es el de las cualidades que ahora debe tener como tutor acompañante virtual en el aprendizaje autónomo.

Líneas arriba se expone a los Entornos Virtuales de Aprendizaje como momentos espacio temporales donde hay encuentros sincrónicos con el docente pero además el componente de auto formador del alumno es esencial para su progreso. Se dilucidaron ventajas que el 
docente diseñador dentro del método proyectual ya maneja y puede establecerlos en este nuevo entorno. Otra de las cualidades del mismo es el de haber ejercido siempre como tutor no solo del estudiante sino del proyecto que el desarrolla. En el modelo proyectual de avances y constantes retroalimentaciones a partir de la problemática de diseño es oportuno rescatar en este manifiesto ciertas características que la nueva figura de tutor debe tener, entre las cuales vamos a analizar las siguientes:

1. Comunicador asertivo. Sin importar que hoy por hoy media un monitor entre ambos actores, estudiante, profesor las habilidades comunicativas deben no solo permanecer sino amplificarse. Tomando en cuenta la definición que nos ofrece García (2007, p.186), la asertividad es la habilidad personal para expresar nuestros deseos de una manera amable, franca, abierta, directa y adecuada, logrando decir lo que queremos sin atentar contra los demás. Negociando con ellos su cumplimiento. Nuevamente este es un concepto que en el ámbito de la tutoría virtual de Diseño se debe practicar con cuidado y meticulosidad. Se recuerda que en el plano proyectual se trata sobre las ideas, las propuestas, las soluciones de Diseño y no existe una mala o buena solución, existen diseños que responden a la problemática o no responden y eso marca las pautas y el respeto hacia el proyecto, por lo tanto al estudiante y al proceso mismo del profesor. Desde este enfoque de la metodología proyectual entonces un tutor asertivo será capaz de comunicarse con sus estudiantes exigiendo resultados, motivando y negociando ideas en pro del avance del proyecto. Respetando los derechos de los estudiantes y expresando sus observaciones de forma clara y convincente.

2. Debe ser un ente motivador. Ya se ha venido explicando en este tratado que el rol docente en la virtualidad tiene una nueva identidad omnipresente pero encapsulado en la pantalla. Esta cualidad no es para nada una desventaja para motivar los procesos cognitivos del estudiante, al contrario ha podido inmiscuirse en el mundo digital de videos, mensajes, reels, en el que viven y se alimentan los mismos. Desde un cierto punto de vista el docente debe verse como un actor más en una red social que ahora es el Entorno Virtual de Aprendizaje y desde este terreno motivar a los alumnos. Ya no es un comunicador pasivo o expositor magistral de recursos y actividades, sino un cooperador activo que motiva y armoniza los encuentros sincrónicos que en la metodología proyectual son vitales en tanto y cuanto se intercambian ideas que pueden construir el proyecto final. La tutoría es una acción educativa con una fuerte base comunicacional que debe estimular en los estudiantes un proceso de cambio de actitud positiva frente a la modalidad virtual, es un intento de cooperación y ayuda adecuada para que un estudiante sea capaz de resolver la problemática de Diseño y avance hacia el logro de los objetivos propuestos en el contenido curricular. 3. Componente de sensibilidad humana. La práctica del seguimiento tutorial es un componente curricular fuera de horarios que depende de la empatía frente a las dudas individuales o grupales que puedan surgir y deben ser abordadas desde un punto que no interrumpa la cronología de la clase sino más bien iguale y empate estos criterios al normal desenvolvimiento de objetivos curriculares.

Entonces esta empatía y sensibilidad humana del tutor debe traducirse en acciones concretas, en este estudio se sugiere que desde la comunicación con sus estudiantes se plan- 
teen encuentros oportunos de realimentación, sin esperar que el estudiante en problemas lo solicite. Estos contactos individuales o colectivos, van por vía pública o privada, minimizando posibles situaciones de aislamiento o retraso en quienes por alguna razón u otra no estén al ritmo de los objetivos. Estas acciones requieren de mucho tacto y monitoreo constante de los resultados de aprendizaje previstos. Es una tarea minuciosa, sí, pero es parte del componente de ser un agente activo y promotor del conocimiento.

La empatía es parte de la comunicación efectiva en un espacio virtual de aprendizaje retomando lo que plantea de Paulo Freire (Ferrari, 2008, p.1) uno de los momentos claros de aprendizaje es aquél en el cual el educador se entera de lo que el alumno conoce, pero no solamente para poder avanzar en la enseñanza del contenido, sino, y principalmente, para traer la cultura del aprendiente dentro del salón de clases.

Este acertado estamento pone al docente diseñador en un compromiso; además de ser empático y poder entablar mecanismos de relación con el estudiante debe conocer, si bien no con profundidad, quien es, porque no responde al contenido curricular, al menos cuáles son sus inquietudes y aspiraciones de la materia y del proyecto en sí. Qué habilidades quiere desarrollar, cuáles son sus expectativas al haber escogido esta carrera. Son aristas básicas de encuentros y diálogo. Se debe recordar que el diálogo empático es uno de los pilares de la comunicación efectiva en ambientes virtuales, el poner en valor el conocimiento de mundo del alumno y su cultura. Quizá estos aspectos estén un poco de lado en los contenidos y objetivos curriculares pero es ahora, dentro de la educación virtual que deben ser retomados.

\section{Conclusiones}

Más allá de establecer estas recomendaciones que son válidas para todos los espacios virtuales no solamente para los espacios de clases virtuales de Diseño Gráfico. Este artículo pretende que el docente encuentre puntos de coincidencia y convergencia en los modelos de nuevas clases virtuales con los empleados en sus metodologías proyectuales y los vaya adaptando y aplicando Y por otra parte el entender desde una nueva óptica y desde la lógica gráfica su nueva presencialidad frente a su alumno, ya no es un actor presente físicamente, es una imagen onmipresente mediado por un monitor y es en este nuevo lenguaje donde debe centrarse y modelar su discurso con nuevos recursos.

Entonces se puede decir como conclusión de esta primera parte donde se ha analizado la nueva presencialidad y omnipresencialidad docente en pantalla, que hay dos vías importantes, la creación de contenidos por parte del profesor y la organización de los mismos dentro de la plataforma aprovechando los tiempos sincrónicos, de encuentro cara a cara con el estudiante o más bien de pantalla a pantalla.

El primer gran paso de creación de contenidos curriculares requiere de una planificación que relacione un método de enseñanza-aprendizaje, en el caso de proyectos de Diseño Gráfico, con un método proyectual y modelo de taller. El siguiente paso es traducirlos al nuevo lenguaje de las pantallas. Como se ha hecho énfasis en este manifiesto, es vital el cómo manejar esta nueva presencialidad en pantalla abstrayendo la estaticidad con elementos participativos concretos. Debate sincrónico y esclarecimiento de dudas es lo que 
Calatrava propone se haga siempre en cada video conferencia, en este estudio se atreve a sugerir el sumar el uso de recursos que apelen al movimiento tanto del estudiante como del maestro, uso de láminas, construcción de moodboards, uso de la pizarra, papelógrafos son las vías. Todo esto registrado en los videos y archivos que conforman el contenido de cada aula virtual, y claro, además articulado dentro de la planificación curricular.

Luego, ya lo que concierne a los encuentros sincrónicos, ellos requieren de un uso especial del tiempo, un aprovechamiento en fomentar el esclarecimiento de las dudas y cubrirlas desde todos los ángulos. Para que esto se dé es indispensable el proceso autónomo del alumno previo a los encuentros y su paralelo desenvolvimiento dentro del aula virtual, que vaya asimilando la información dosificadamente acorde a los objetivos curriculares. En el encuentro con el docente presentará sus necesidades puntuales de acuerdo a su desarrollo individual, además de recibir las directrices que le pueda brindar el docente, así esta esteticidad en el plano se vuelve verdaderamente un diálogo y no una imagen estéril omnipresente y monótona para el estudiante en la sala de su casa, sino más bien se vuelve un espacio que el estudiante busca y solicita ya que encuentra en su mentor los luces para culminar el proyecto.

\section{Dentro de la nueva presencialidad, pantalla}

Como se ha hablado antes, es básico el entender desde la perspectiva del docente las nuevas maneras de enfrentarse a su nueva imagen y omnipresencialidad que se destaca como concepto en este artículo. Para facilitar al mismo, este nuevo auto entenderse y auto proyectarse, se pone de manifiesto los siguientes puntos a seguir como reflexiones útiles y prácticas dentro del nuevo lenguaje visual que el profesor debe manejar desde su monitor que es su nueva identidad.

En primer lugar se propone que el docente maneje su presencialidad ubicándose de distinta manera en el plano, porque no cambiando su ubicación y proporcionado movimiento. Es una técnica básica de los oradores, moverse por el escenario, en este caso la pantalla. Conlleva que el espacio del que dispone el docente sea un poco adaptable y es también, una manera de modificar la herramienta, que no se limite a la laptop sino al manejo del espacio circundante. Entendiéndose espacio además, como lo que atañe al contenido curricular, un plano técnico, un esquema proyectual, un arte final, etc.

En segundo lugar se puede hablar de una idea que se denomina, recortar en fragmentos construidos. La actualidad de los dispositivos móviles que tenemos es fundamental en esta propuesta, esta tecnología al alcance de todos permite que se puedan construir cápsulas audiovisuales asincrónicas, desde otros espacios y desde otros puntos de vista del contenido a tratarse. Se puede aprovechar otro lugar, otra "locación" donde el docente desarrolle la idea y luego pueda ser incluida en la clase habitual. Es cotidiano hoy por hoy tener un video hasta de lo que se come, lo que se visita, lo que se ejercita. Por qué no tomar estos espacios para brindar ideas. El objetivo nuevamente es salir del pantallazo del profesor y enriquecer la conversación con otros ángulos.

Es una actividad que se puede extrapolar a los estudiantes, en el desarrollo del proyecto existen etapas de estudio y análisis que promueven cierta clase de observación de ejemplos de aplicaciones reales a las que pueden estar expuestos en su cotidianidad. Si bien 
existen limitantes de movilidad en la actual normalidad también es cierto que se vive en la era de registrar en video todo, por qué no registrar en video las ideas, los saberes. Los conocimientos que se van desarrollando. Es algo real y cotidiano que debe incluirse en las aulas virtuales, como se apunta, siempre desde las vivencias del docente como también del alumno.

Como tercera sugerencia, se propone involucrar otros actores. En el desenvolvimiento de los contenidos y avances del proyecto. Es también habitual en la convivencia actual el trasmitir y documentar también las interacciones con los demás, un amigo, la pareja, un colectivo. Aquí si existe un problema, la distancia o distanciamiento. Depende del profesor el vincular actores que puedan aportar al contenido desde las herramientas que permiten un contacto remoto, grabaciones de docentes invitados, entrevistas, etc. Y desde el otro actor, el estudiante también puede alimentar sus propuestas, dentro de los casos de estudio de su proyecto. Son vías válidas y que quitan este sabor a estaticidad de la que se habló al inicio de este análisis. Entonces retomando lo expuesto se puede entender que, el realizar cambios estructurales desde el proceso de aprendizaje, es valerse de todos los recursos expresivos al alcance y comprensión tanto del docente como del alumno para construir encuentros en pantalla menos monótonos y mayormente propositivos.

\section{Referencias Bibliográficas}

Calatrava (2019). Transformación digital en la educación: blended learning y flipped classroom o aula invertida. Recuperado de https:/www.d2l.com/es/blog/transformaciondigital-en-la-educacion-blended-learning-y-flipped-classroom-o-aula-invertida/

De Santiago, P. (2016). El cine en 7 películas: guía básica del lenguaje cinematográfico. Madrid: UNED - Universidad Nacional de Educación a Distancia.

Flip learning (2015). Visión - What is a plipped classroom? Del blog The Flipped classroom. Recuperado de https://www.theflippedclassroom.es/what-is-innovacion-educativa/

Ferrari, M. (2008). Paulo Freire, o mentor da Educação para a consciência. Nova Escola. Recuperado el 08 de abril de 2021, de https://novaescola.org.br/conteudo/460/mentoreducacao-consciencia

García Aretio, L. (Coord.) (2007). De la educación a distancia a la educación virtual. Barcelona: Ariel.

García Perea, M. (Coord.) (2015). Tecnología y Aprendizaje Ubicuo. Toluca: Instituto superior de Ciencias de la Educación.

Narváez Torregrosa, D. (2004). Los inicios del cine. Plaza y Valdés, S.A. de C.V. México.

Rama Vitale, C. (2017). Futuro de los Sistemas y Ambientes Educativos mediados por las TIC. Universidad de Guadalajara, Jalisco.

Abstract: This is a question repeatedly asked since the beginning of the change that took 
place in the classroom. Regardless of whether it is applicable or not, the answer is that it must necessarily adapt and evolve accordingly.

From a projective approach, within the field of Graphic Design, where concrete proposals must develop from a conceptual basis, it is inevitable to work with the projective method in a workshop mode, which requires constant feedback on the project's progress. This makes sense insofar as it is possible to elucidate advances and corrections on the proposal presented and developed by the student. The mediation of a technology that bridges the distance carries problems, especially when both parties, teacher, and student, are not "there" to discuss the project. Everything is done on a screen. It is not sketched or schematized tangibly or directly. This is aggravated if the class is not given in synchronicity.

The proposal is that the ICT adaptation that mediates the process also depends on the adaptation of the teacher's method-emphasizing the new protagonism of the teacher whose identity is nowadays, an omnipresent screen that can be present in all the student's environments. The proposal is to find the core points of a teacher's resignification as a new image supported by an audiovisual language where the modification of both the pedagogical and attitudinal model in the synchronous and asynchronous meetings can become advantageous within the curricular improvement

Keywords: Technology - Ubiquitous - Omnipresenciality - Flipped classroom.

Resumo: É possível aplicar o método de projeto tradicional em ambientes virtuais de aprendizagem. É uma pergunta que se repete desde o momento da mudança que está sendo vivida. Independentemente de ser ou não aplicável, a resposta é que necessariamente tem que se adaptar e evoluir, de acordo.

A partir de uma abordagem de temas projetivos, no âmbito do Design Gráfico, onde as propostas tangíveis devem ser desenvolvidas a partir de uma base conceitual, é inevitável trabalhar com o método projetivo, numa modalidade de oficina que exige um feedback constante sobre o andamento do projeto. Isso faz sentido na medida em que avanços e correções possam ser elucidados na proposta feita pelo aluno. Por serem mediados por uma tecnologia que elimina a distância, existem problemas, especialmente porque ambas as partes, professor e aluno, não estão "lá" para discutir. Tudo é feito em uma tela. Não é esboçado ou delineado tangivelmente ou diretamente, isto é agravado se a aula não for dada em sincronicidade.

Propõe-se que a adaptação das TIC que medeiam o processo depende também da adaptação do método do professor. Enfatizando o novo papel do professor cuja identidade é hoje, uma tela onipresente em todos os ambientes dos alunos. A ideia é encontrar os pontos centrais de uma ressignificação do professor como uma nova imagem sustentada por uma linguagem audiovisual onde a modificação dos modelos pedagógico e atitudinal em encontros síncronos e assíncronos possa ser benéfica no aprimoramento curricular.

Palavras chave: Tecnologia - omnipresente - omnipresencial - sala de aula invertida.

[Las traducciones de los abstracts fueron supervisadas por el autor de cada artículo] 